\title{
Socio-economic impacts of brucellosis on livestock production and reproduction performance in Koibatek and Marigat regions, Baringo County, Kenya
}

\author{
Peter N. Lokamar ${ }^{1,2}$, Moses A. Kutwah ${ }^{3}$, Harrysone Atieli ${ }^{1}$, Sussy Gumo ${ }^{4}$ and Collins Ouma ${ }^{5^{*}}$ (D)
}

\begin{abstract}
Background: Brucellosis in Africa is caused by Brucella species transmitted through contaminated or contacts with infected animals or their carcasses. The disease reduces livestock production and reproduction performance evident by frequent episodes of abortion, still births, swollen testes, weak calves/lambs and swollen joints. However, the socio-economic impacts of these brucellosis-associated symptoms on milk, fat, meat and blood production, infertility, sale value, dowry and costs of treatment has not been evaluated extensively in developing countries. In Baringo County, Kenya, there is a continuous movement of cattle as a result of trade and grazing, which predisposes many herds to brucellosis infection. The objective of this study was to investigate the socio-economic impacts of Brucella infection on production systems for sheep, goats, cattle and camels and explore the impact of brucellosis on livestock production and reproduction performance among livestock keeping communities in Baringo County, Kenya. The study adopted a cross-sectional survey using quantitative data collection methods.

Results: Results demonstrated an impact on milk production in suspected brucellosis cases resulting from abortions $(\mathrm{OR}=0.151, P<0.0001)$ and swollen joints $(\mathrm{OR}=2.881, P<0.0001)$. In terms of infertility, abortion as a symptom of brucellosis $(\mathrm{OR}=0.440, P=0.002)$, still birth $(\mathrm{OR}=0.628, P=0.042)$, and weak calf or lamb $(\mathrm{OR}=0.525, P=0.005)$ had an impact on infertility. In terms of sale value, abortion $(\mathrm{OR}=0.385, P=0.008)$, weak calf/lamb $(\mathrm{OR}=2.963, P=0.013)$ had an impact on sale value. Other analyses demonstrated that for dowry, swollen testes $(O R=5.351, P=0.032)$, weak calf and lambs ( $O R=0.364, P=0.019)$ had a likelihood of reduction of dowry value. Finally, in terms of cost of treatment, abortion $(O R=0.449, P=0.001)$, still births $(O R=0.208, P=0.015)$, swollen testes $(O R=0.78, P=0.014)$, weak calf/lambs $(\mathrm{OR}=0.178, P=0.007)$ and swollen joints $(\mathrm{OR}=0.217, P=0.003)$ significantly increased the costs of treatments. There was no impact on fat and meat and blood production.

Conclusion: Even though there was a huge socio-economic impact on milk production, infertility, sale value, and dowry, it was the costs of treatment that was significantly impacted on all symptoms associated with brucellosis on this community. A 'One Health' approach in tackling the brucellosis menace as a holistic approach is recommended for both humans and their livestock.
\end{abstract}

Keywords: Brucellosis, Farmers, Perceived impact, Baringo County, Kenya

\footnotetext{
* Correspondence: collinouma@yahoo.com

${ }^{5}$ Department of Biomedical Sciences and Technology, School of Public

Health and Community Development, Maseno University, Kisumu, Kenya

Full list of author information is available at the end of the article
}

(c) The Author(s). 2020 Open Access This article is distributed under the terms of the Creative Commons Attribution 4.0 International License (http://creativecommons.org/licenses/by/4.0/), which permits unrestricted use, distribution, and reproduction in any medium, provided you give appropriate credit to the original author(s) and the source, provide a link to the Creative Commons license, and indicate if changes were made. The Creative Commons Public Domain Dedication waiver (http://creativecommons.org/publicdomain/zero/1.0/) applies to the data made available in this article, unless otherwise stated. 


\section{Introduction}

Globally, brucellosis is described as a highly contagious zoonotic disease, and a cause of significant reproductive losses in livestock [1]. In Africa, brucellosis is described as enzootic and is common in low- and middle-income countries (LMICs). The disease caused by Brucella species (B. abortus, B. mellitensis, and B. suis) is transmitted through contaminated and unpasteurized milk, milk products or by direct contact with infected animals or animal carcasses [2]. Abortion constituents, uterine exudates and colostrum are highly infectious [3]. Animal brucellosis causes direct socio-economic effects in communities who depend on animal production for their livelihood. Losses in animals are attributed to direct effects on their offspring due to abortion, stillbirth and infertility whereas indirect losses are due to reduction in milk yields and humans suffering resulting from the disease [4].

In LMICs, the prevalence of animal and human brucellosis is generally unknown due to a myriad of challenges with diagnostics, reporting and weak to non-existent surveillance systems, especially in malaria endemic areas $[5,6]$ with variations based on the pastoral systems.

Although prevalence is high and variable in many countries, surveillance for the disease is generally poor [7]. Factors assumed to be responsible for variation in prevalence include purchase of infected cattle from the market for replacement or upgrading, nature of animal production, sharing of bulls, use of open-range grazing, demographic factors, regulatory issues, and climate and wildlife interaction [7]. Furthermore, one major factor contributing to the spread of the disease is the free movement of animals practiced by the livestock keepers in regions such as in Baringo County, Kenya. Despite under-reporting and inadequate epidemiologically valid data, the evidence obtained throughout the years illustrate that brucellosis is a widespread problem in Africa, a continent where several Sub-Saharan countries are estimated to bear a high burden of neglected zoonotic diseases $[2,8]$.

In terms of socio-economic effects, it has been documented that most quantifiable expressions of Brucella are linked to reproduction [2]. For example, infected male animals were prone to infertility and reduced reproductive performance. Female animals, on the other hand, suffered from abortion, stillbirth and early death of offspring when the uterus gets infected. In addition to spreading the infection to humans, animal brucellosis impacts livestock productivity, which can have adverse socio-economic and indirect health consequences on humans, especially helpless livestock-keeping populations in resource-limited surroundings that depend on livestock for food security and income [2].

The impacts of brucellosis in livestock include abortion and death as well as decreased milk and meat production and reduced reproductive efficiency [9]. Generally, the costs associated with the treatment in animals attributed to diseases such as brucellosis is remarkably high [10, 11]. As the disease is hardly remarkable in its chronic stage and despite the losses and yield decrease, its causes often goes unnoticed. Its negative effect on cost-effectiveness of livestock production is extremely undervalued particularly in tropical areas in wide-ranging management system [12]. Brucellosis illness to the herds reduces livestock production and reproduction performance evident by frequent episodes of abortion especially during the last trimester, retention of placenta, metritis, birth of weak calves, infertility in bulls and cows and $20 \%$ reduction in milk production from infected cows $[13,14]$.

In Baringo County, where the current study was conducted, brucellosis prevalence is unknown due to lack of awareness among communities about the disease, but more importantly due to weakened animal and public health systems owing to the remoteness of the region and insecurity. As a consequence, the disease remains largely neglected with little attention given to prevention and control in livestock and humans [15]. In this region of study, there is a continuous movement of cattle as a result of trade and for grazing, which then predisposes many herds to brucellosis infection [15]. Owing to the difficulty in gathering accurate data on the persistence and disease prevalence of brucellosis in pastoral communities the information remains scarce. Studies on the socio-economic effects of Brucella infection on reproductive conditions are generally rare in Kenya. As much as it is widely known that infection with brucellosis has socio-economic impacts, the actual impact on livestock production and reproduction performance in agrarian and nomadic regions in Baringo County remain unestablished. As such the objective of this study was to investigate the socio-economic impacts of Brucella infection on production systems of indigenous, mixed and exotic breeds (sheep, goats, cattle and camels) and explore the impact of brucellosis on livestock production and reproduction performance among livestock keeping communities in Baringo County, Kenya.

\section{Results}

\section{Response rate}

The final sample size obtained was 640 herds; (320 bovine, 106 camel, 154 goat and 60 sheep) from 604 households.

\section{Demographic characteristics of the study population}

This study targeted households with domestic ruminants; cattle, goats, sheep and camels. Livestock keepers who were in close contact with the animals were the key respondents for interview and were enrolled as study participants. The study was conducted in Baringo County and targeted 8 locations in Koibatek and Marigat sub-counties; Torongo, Koibatek, Ravine, Lembus Kwen, Marigat, Eldume, Kimalel and 
Loboi. The study revealed that $67.5 \%$ of residents in Marigat Sub-county and $32.5 \%$ of residents in Koibatek Sub-county reared domestic ruminants. Majority of the animals reared were females $54.5 \%(n=349)$. Most of the animals reared were aged $\geq 3$ years, $43.0 \%$ ( $n=275), 2-3$ years $38.1 \%(n=$ $244)$ and a few aged 2 years and below $18.9 \%(n=121)$. Domesticated animals were as follows: $68.3 \%$ were indigenous breeds, $74.3 \%$ utilized natural breeding system and $34.4 \%$ adopted mixed farming as the primary type of production system. The main source of drinking water for livestock was river (37.7\%) and borehole (36.6\%) (Table 1).

\section{Reported socio-economic impact of brucellosis on livestock production and reproduction performance}

The association between socio-economic factors and abortion, still birth, retained placenta, swollen joints, swollen testes, weak calf or lamb, repeat breeder and apparent infertility as consequences of brucellosis was performed. In addition, the perceived socio-economic impact on milk, meat and blood, fat, infertility, sale value, dowry and cost of treatment against abortion was assessed. Results revealed that the proportions of those who indicated that brucellosis had an impact on milk production was either medium (54.1\%) or high (6.8\%), meat and blood as medium $(54.4 \%)$ or high $(5.7 \%)$, infertility $(66.0 \%)$, sale value as medium (64.3\%) or high (5.7\%), dowry (50.1\%) and cost of treatment as medium (62.3\%) or high (33.7\%). All these proportions were significantly higher (all at $P<$ 0.0001). However, the proportions of those who said the effects was high, medium or had no impact on fat production were comparable $(P=0.127)$.

Further regression analyses indicated that there was $85 \%$ impact on milk production in suspected brucellosis cases $\quad(\mathrm{OR}=0.151,95 \% \quad \mathrm{CI}=0.066-0.342, \quad P<0.0001)$. Furthermore, results demonstrated that there was $56 \%$ impact on infertility $(\mathrm{OR}=0.440,95 \% \mathrm{CI}=0.261-0.743$, $P=0.002), 62 \%$ reduction on sale value $(\mathrm{OR}=0.385,95 \%$ $\mathrm{CI}=0.190-0.776, P=0.008), 56 \%$ increment on cost of treatment $(\mathrm{OR}=0.449,95 \% \mathrm{CI}=0.281-0.717, P=0.001)$. Even though it indicated that there was significantly no loss to fat $(\mathrm{OR}=3.156,95 \% \mathrm{CI}=1.152-8.646, P=0.025)$, there was no effect on dowry $(P=0.829)$ and meat and blood production $(P=0.220)$ (Table 2 ).

Perceived socio-economic impact associated with still birth as a result of brucellosis on milk, meat and blood, infertility, sale value, dowry and cost of treatment was assessed. Results showed the proportions of those who indicated that stillbirth had an impact on the following; milk as medium (64.9\%) or high (6.9\%), meat and blood, medium $(64.9 \%)$ or high $(4.8 \%)$, sale value as medium $(71.4 \%)$ or high $(5.6 \%)$, cost of treatment as medium $(67.5 \%)$ or high $(31.2 \%)$, infertility $(66.7 \%)$ and dowry (58.9\%). All these proportions were significant (all $\mathrm{P}<$ $0.0001)$. However, the proportion of respondents who said still birth had high, medium or had no impact on fat $(60.6 \%)$ was comparable at $(P=0.062)$ (Table 3$)$.

Logistics regression model with still birth as dependent variable was established to determine socio-economic status influence on still birth. There was 38\% impact on infertility $(\mathrm{OR}=0.628,95 \% \mathrm{CI}=0.402-0.983, P=0.042)$ and $80 \%$ increment on cost of treatment in suspected brucellosis cases $(\mathrm{OR}=0.208, \quad(95 \% \mathrm{CI}=0.059-0.738$, $P=0.015)$. On the contrary, no significant effect was attributed to milk production $(P=0.800)$, meat and blood production $(P=0.560)$, fat production $(P=0.594)$, dowry $(P=0.723)$ and sale value $(P=0.133)$ (Table 3$)$.

We further assessed the socio-economic impact of swollen testes as a sign of suspected brucellosis on the same products: milk, meat and blood, infertility, sale value, dowry and cost of treatment. The following were the proportions of those who specified that swollen testes had impact on production: milk (67.3\%), infertility (64.2\%), dowry (56.6\%), meat and blood as medium $(63.5 \%)$ or high $(5.0 \%)$, fat as medium $(61.7 \%)$ or high (2.9\%), sale value as medium $(71.1 \%)$ or high $(5.7 \%)$, cost of treatment as medium $(66.7 \%)$ or high $(32.7 \%)$. The proportions of those who indicated that it had an impact on sale value $(P<0.0001)$, dowry $(P<0.0001)$ and cost of treatment $(P<0.0001)$, meat and blood $(P=0.002)$, milk $(P=0.004)$ and infertility $(P=0.003)$ was significantly higher than those who indicated it had no impact. However, the proportions of those who said fat (61.7\%) had or had no impact on swollen testes was comparable $(P=$ 0.100) (Table 4).

Logistics regression analysis established that there was 5 times more impact on dowry $(\mathrm{OR}=5.351,95 \% \mathrm{CI}=$ 1.159-24.706, $P=0.032$ ) and $22 \%$ increment on cost of treatment $(\mathrm{OR}=0.78,95 \% \mathrm{CI}=0.10-0.598, P=0.014)$. Even so, the proportions of those who indicated that it had impact versus no impact were comparable between loss in milk production $(P=0.670)$, meat and blood production $(P=0.841)$, fat production $(P=0.233)$, infertility $(P=0.857)$ and sale value $(P=0.122)$ in animals suspected to suffer from brucellosis (Table 4).

We additionally reported on the socio-economic impact related to weak calf or lamb as a result of suspected brucellosis on milk, meat and blood, infertility, sale value, dowry and cost of treatment. Results exhibited that the proportions of those who specified that weak calf or lamb had impact on were significantly higher for milk as medium $(61.7 \%)$ or high $(8.7 \%)$ meat and blood as medium $(63.5 \%)$ or high $(5.6 \%)$, sale value as medium $(66.5 \%)$ or high $(5.2 \%)$, cost of treatment as medium $(63.9 \%)$ or high $(34.8 \%)$, infertility $(73.5 \%)$, and fat (60.2\%) (all $P<0.0001$ ), while for fat it was at $P=0.029$. However, the proportions of those who said dowry (61.3\%) had or had no impact on weak calf or lamb was comparable $(P=0.052)$ (Table 5$)$. 
Table 1 Demographic Characteristics of the Study Population

\begin{tabular}{|c|c|c|}
\hline Characteristic $(n=640)$ & Frequency & Percentage (\%) \\
\hline \multicolumn{3}{|l|}{ Species per Sub-county } \\
\hline Marigat & 432 & $67.5 \%$ \\
\hline Bovine & 114 & $26.4 \%$ \\
\hline Sheep & 58 & $13.4 \%$ \\
\hline Goat & 154 & $35.6 \%$ \\
\hline Camel & 106 & $24.5 \%$ \\
\hline Koibatek & 208 & $32.5 \%$ \\
\hline Bovine & 206 & $99.0 \%$ \\
\hline Sheep & 2 & $1.0 \%$ \\
\hline Goat & 0 & $0 \%$ \\
\hline Camel & 0 & $0 \%$ \\
\hline \multicolumn{3}{|l|}{ Gender of the animals } \\
\hline Male & 291 & $45.5 \%$ \\
\hline Female & 349 & $54.5 \%$ \\
\hline \multicolumn{3}{|c|}{ Age of the species in years } \\
\hline Bovine & 320 & $50.0 \%$ \\
\hline$<2$ years & 47 & $38.8 \%$ \\
\hline $2-3$ years & 109 & $44.7 \%$ \\
\hline$>3$ years & 164 & $59.6 \%$ \\
\hline Sheep & 60 & $9.4 \%$ \\
\hline$<2$ years & 13 & $10.7 \%$ \\
\hline $2-3$ years & 29 & $11.9 \%$ \\
\hline$>3$ years & 18 & $6.5 \%$ \\
\hline Goat & 154 & $24.1 \%$ \\
\hline$<2$ years & 45 & $37.2 \%$ \\
\hline $2-3$ years & 66 & $27.0 \%$ \\
\hline$>3$ years & 43 & $15.6 \%$ \\
\hline Camel & 106 & $16.6 \%$ \\
\hline$<2$ years & 16 & $13.2 \%$ \\
\hline $2-3$ years & 40 & $16.4 \%$ \\
\hline$>3$ years & 50 & $18.2 \%$ \\
\hline Types of breeds & (Cumulative frequencies) & \\
\hline Indigenous & 441 & $68.3 \%$ \\
\hline Exotic & 205 & $31.7 \%$ \\
\hline \multicolumn{3}{|c|}{ Type of production system } \\
\hline Nomadic pastoralist & 218 & $23.6 \%$ \\
\hline Agro-pastoralist & 135 & $14.6 \%$ \\
\hline Mixed farming & 318 & $34.4 \%$ \\
\hline Commercial ranch & 8 & $0.9 \%$ \\
\hline Peri-urban & 25 & $2.7 \%$ \\
\hline Semi-zero grazing & 220 & $23.8 \%$ \\
\hline \multicolumn{3}{|l|}{ Type of breeding system } \\
\hline Artificial insemination & 176 & $25.7 \%$ \\
\hline Natural & 508 & $74.3 \%$ \\
\hline
\end{tabular}

Table 1 Demographic Characteristics of the Study Population (Continued)

\begin{tabular}{lll}
\hline Characteristic $(n=640)$ & Frequency & Percentage (\%) \\
\hline Main source of drinking water for livestock & \\
Pond & 63 & $9.8 \%$ \\
Borehole & 234 & $36.6 \%$ \\
River & 241 & $37.7 \%$ \\
Compound trough & 102 & $15.9 \%$ \\
\hline
\end{tabular}

Presented are $\mathrm{N}(\%)$ for all categories

This assessment further explored on how weak calf/ lamb influenced socio-economic status of the households. There was $64 \%$ likelihood of reduction of dowry value $(\mathrm{OR}=0.364,95 \% \mathrm{CI}=0.157-0.845, P=0.019), 2$ times reduction in sale value $(\mathrm{OR}=2.963,95 \% \mathrm{CI}=1.258-6.982$, $P=0.013), 48 \%$ increased chances of infertility $(\mathrm{OR}=$ $0.525,95 \% \mathrm{CI}=0.333-0.827, P=0.005)$ and $83 \%$ possibility on increment in cost of treatment $(\mathrm{OR}=0.178,95 \%$ $\mathrm{CI}=0.051-0.622, P=0.007)$ in suspected brucellosis instances. From the model, there was no significant effect on milk production $(P=0.680)$, meat and blood production $(P=0.464)$ and fat production $(P=0.487)$ (Table 5$)$.

We finally assessed the socio-economic impact on milk, meat and blood, fat, infertility, sale value, dowry and cost of treatment as a result of swollen joint, as part of suspected brucellosis. The outcome demonstrated that the proportions of those who pointed out that brucellosis had an impact of milk production was (43.1\%), meat and blood (49.0\%), sale value (53.9\%) and dowry (46.1\%). Infertility was reported as medium $(32.3 \%)$ and high $(52.0 \%)$ whereas the proportion of those indicating cost of treatment being medium (39.2\%) and high $(59.8 \%)$. All these proportions were significantly higher $(P<0.0001)$ relative to those who said there was no impact. However, the proportions of those who said brucellosis had or had no impact on fat production were comparable $(P=0.114)$ (Table 6).

Further logistic regression analyses demonstrated almost 3 times likelihood of reduction in milk production $(\mathrm{OR}=2.881,95 \% \mathrm{CI}=1.733-4.790, P<0.0001)$ and $\mathrm{a}$ $79 \%$ likely increase in cost of treatment $(\mathrm{OR}=0.217$, $95 \% \mathrm{CI}=0.79-0.594, P=0.003)$ in animals suspected to be ailing from brucellosis. However, there was no association on meat and blood $(P=0.980)$, fat $(P=0.093)$, infertility $(P=0.603)$, sale value $(P=0.267)$ and dowry $(P=$ 0.711) (Table 6).

\section{Discussion}

Brucellosis is considered a neglected disease that significantly affects countries where resources are limited, and as such, there are only a few studies that has measured the socio-economic impact of brucellosis in livestock. Even though the estimated socio-economic impacts vary with 
Table 2 Reported impact of abortion on socio-economic status

\begin{tabular}{|c|c|c|c|c|c|c|c|c|c|}
\hline \multirow[t]{3}{*}{ Variables } & \multicolumn{4}{|c|}{ Abortions $^{a}$} & \multirow[t]{3}{*}{$x^{2}$} & \multirow[t]{3}{*}{$P$-value } & \multirow[t]{3}{*}{$O R$} & \multirow[t]{3}{*}{$95 \% \mathrm{Cl}$} & \multirow[t]{3}{*}{$P$-value } \\
\hline & \multicolumn{2}{|l|}{ Yes } & \multicolumn{2}{|l|}{ No } & & & & & \\
\hline & $n$ & $\%$ & $n$ & $\%$ & & & & & \\
\hline \multicolumn{10}{|l|}{ Milk } \\
\hline High & 24 & 6.8 & 86 & 30.0 & 62.9 & $<0.0001^{*}$ & 0.151 & $0.066-0.342$ & $<0.0001^{*}$ \\
\hline Medium & 191 & 54.1 & 133 & 46.3 & & & & & \\
\hline Low & 138 & 39.1 & 68 & 23.7 & & & & & \\
\hline \multicolumn{10}{|c|}{ Meat and blood } \\
\hline High & 20 & 5.7 & 58 & 20.2 & 36.4 & $<0.0001^{*}$ & 0.541 & $0.203-1.444$ & 0.220 \\
\hline Medium & 192 & 54.4 & 154 & 53.7 & & & & & \\
\hline Low & 141 & 39.9 & 75 & 26.1 & & & & & \\
\hline \multicolumn{10}{|l|}{ Fat } \\
\hline High & 15 & 4.2 & 21 & 7.3 & 4.1 & 0.127 & 3.156 & $1.152-8.646$ & $0.025^{*}$ \\
\hline Medium & 185 & 52.4 & 158 & 55.1 & & & & & \\
\hline Low & 153 & 43.3 & 108 & 37.6 & & & & & \\
\hline \multicolumn{10}{|l|}{ Infertility } \\
\hline High & 100 & 28.3 & 134 & 46.7 & 23.1 & $<0.0001^{*}$ & 0.440 & $0.261-0.743$ & $0.002^{*}$ \\
\hline Medium & 133 & 37.7 & 77 & 26.8 & & & & & \\
\hline Low & 120 & 34.0 & 76 & 26.5 & & & & & \\
\hline \multicolumn{10}{|l|}{ Sale value } \\
\hline High & 20 & 5.7 & 67 & 13.6 & 48.7 & $<0.0001^{*}$ & 0.385 & $0.190-0.716$ & $0.008^{*}$ \\
\hline Medium & 227 & 64.3 & 126 & 55.2 & & & & & \\
\hline Low & 106 & 30.0 & 94 & 31.3 & & & & & \\
\hline \multicolumn{10}{|l|}{ Dowry } \\
\hline High & 16 & 4.5 & 37 & 12.9 & 19.6 & $<0.0001^{*}$ & 0.912 & $0.396-2.101$ & 0.829 \\
\hline Medium & 161 & 45.6 & 143 & 49.8 & & & & & \\
\hline Low & 176 & 49.9 & 107 & 37.3 & & & & & \\
\hline \multicolumn{10}{|c|}{ Cost of treatment } \\
\hline High & 119 & 33.7 & 159 & 55.4 & 34.5 & $<0.0001^{*}$ & 0.449 & $0.281-0.717$ & $0.001^{*}$ \\
\hline Medium & 220 & 62.3 & 112 & 39.0 & & & & & \\
\hline Low & 14 & 4.0 & 16 & 5.6 & & & & & \\
\hline
\end{tabular}

apearson Chi-square. *Statistically significant at $P \leq 0.05$. OR odds ratio, 95\% Cl 95\% Confidence Interval. OR generated through logistic regression analyses

the location, production system, facilities, and miscellaneous factors including indirect health effects of the disease in humans [16], the current study focused on respondent's perceived socio-economic impact of brucellosis on livestock production and reproduction performance with a focus on milk, meat and blood, and fat production, infertility, sale value, dowry and cost of treatment relative to suspected brucellosis symptoms (abortions, still births, swollen testes, weak calf or lamb, and swollen joints). The current study was focused in Baringo County, since in this region, brucellosis prevalence is unknown due to weakened animal and public health systems majorly attributed by the remoteness of the region and a huge insecurity making it almost impossible to carry out detailed analyses on the Brucella disease dynamics in the population.
Consequently, the disease still remains essentially neglected with little attention given to prevention and control in livestock and humans, with a continuous movement of cattle, which then predisposes many herds to brucellosis infection [15].

Our results demonstrated that there was $85 \%$ impact on milk production in suspected brucellosis cases resulting from abortions $(\mathrm{OR}=0.151,95 \% \mathrm{CI}=0.066-0.342$, $P<0.0001)$ and almost 3 times likelihood of reduction in milk production $(\mathrm{OR}=2.881,95 \% \mathrm{CI}=1.733-4.790, P<$ 0.0001 ) as a result of swollen joints. However, there was no impact of stillbirth, swollen testes and weak calf and lambs on milk production as reported by farmers in this region. In previous studies carried out in other settings [17], it was demonstrated that mastitis suspected to be 
Table 3 Reported impact of still birth on socio-economic status

\begin{tabular}{|c|c|c|c|c|c|c|c|c|c|}
\hline \multirow[t]{3}{*}{ Variables } & \multicolumn{4}{|c|}{ Still birth ${ }^{a}$} & \multirow[t]{3}{*}{$x^{2}$} & \multirow[t]{3}{*}{ P-value } & \multirow[t]{3}{*}{$O R$} & \multirow[t]{3}{*}{$95 \% \mathrm{Cl}$} & \multirow{3}{*}{$\begin{array}{l}P- \\
\text { value }\end{array}$} \\
\hline & \multicolumn{2}{|l|}{ Yes } & \multicolumn{2}{|l|}{ No } & & & & & \\
\hline & $n$ & $\%$ & $n$ & $\%$ & & & & & \\
\hline \multicolumn{10}{|l|}{ Milk } \\
\hline High & 16 & 6.9 & 94 & 23.0 & 38.6 & $<0.0001^{*}$ & 2.122 & $0.913-4.933$ & 0.800 \\
\hline Medium & 150 & 64.9 & 174 & 42.5 & & & & & \\
\hline Low & 65 & 28.1 & 141 & 34.5 & & & & & \\
\hline \multicolumn{10}{|c|}{ Meat and blood } \\
\hline High & 11 & 4.8 & 67 & 16.4 & 25.5 & $<0.0001^{*}$ & 0.854 & $0.501-1.455$ & 0.560 \\
\hline Medium & 150 & 64.9 & 196 & 47.9 & & & & & \\
\hline Low & 70 & 30.3 & 146 & 35.7 & & & & & \\
\hline \multicolumn{10}{|l|}{ Fat } \\
\hline High & 7 & 3.0 & 29 & 7.1 & 5.6 & $0.062^{*}$ & 1.139 & $0.706-1.836$ & 0.594 \\
\hline Medium & 133 & 57.6 & 210 & 51.3 & & & & & \\
\hline Low & 91 & 39.4 & 170 & 41.6 & & & & & \\
\hline \multicolumn{10}{|l|}{ Infertility } \\
\hline High & 49 & 21.2 & 185 & 45.2 & 41.7 & $<0.0001^{*}$ & 0.628 & $0.402-0.983$ & $0.042^{*}$ \\
\hline Medium & 105 & 45.5 & 105 & 25.7 & & & & & \\
\hline Low & 77 & 33.3 & 119 & 29.1 & & & & & \\
\hline \multicolumn{10}{|l|}{ Sale value } \\
\hline High & 13 & 5.6 & 74 & 18.1 & 42.2 & $<0.0001^{*}$ & 0.684 & $0.416-1.123$ & 0.133 \\
\hline Medium & 165 & 71.4 & 188 & 46.0 & & & & & \\
\hline Low & 53 & 22.9 & 147 & 35.9 & & & & & \\
\hline \multicolumn{10}{|l|}{ Dowry } \\
\hline High & 8 & 3.5 & 45 & 11.0 & 15.7 & $<0.0001^{*}$ & 1.091 & $0.674-1.767$ & 0.723 \\
\hline Medium & 128 & 55.4 & 176 & 43.0 & & & & & \\
\hline Low & 95 & 41.1 & 188 & 46.0 & & & & & \\
\hline \multicolumn{10}{|c|}{ Cost of treatment } \\
\hline High & 72 & 31.2 & 206 & 50.4 & 38.5 & $<0.0001^{*}$ & 0.208 & $0.059-0.738$ & $0.015^{*}$ \\
\hline Medium & 156 & 67.5 & 176 & 43.0 & & & & & \\
\hline Low & 3 & 1.3 & 27 & 6.6 & & & & & \\
\hline
\end{tabular}

aPearson Chi-square. *Statistically significant at $P \leq 0.05$. OR odds ratio, 95\% Cl 95\% Confidence Interval. OR generated through logistic regression analyses

resulting from brucellosis infection led to reduction in milk production in cattle. Even though mastitis was not evaluated in the current study, the findings in the previous study is generally consistent with our observations that suspected brucellosis infection symptoms are directly related to reduced mild production. Other observations in Tanzania have noted that despite immunizations with Brucella (B.) abortus RB51 vaccine, a rise in abortions suspiciously caused by Brucella was still eminent in a dairy cattle herd [18]. They further indicated that the disease has serious economic implications resulting from abortions, infertility and decreased milk production, thus necessitating the implementation of surveillance and control strategies to forestall the socio- economic effects in both developed and developing countries where the disease is endemic.

In terms of infertility, our study demonstrated that abortion as a symptom of brucellosis had a $56 \%$ impact on infertility $(\mathrm{OR}=0.440,95 \% \mathrm{CI}=0.261-0.743, P=$ $0.002)$, there was a $38 \%$ impact on infertility $(\mathrm{OR}=$ $0.628,95 \% \mathrm{CI}=0.402-0.983, P=0.042$ ) resulting from still birth, and $48 \%$ increased chances of infertility (OR $=$ $0.525,95 \% \mathrm{CI}=0.333-0.827, P=0.005)$ due to weak calf or lamb. Even though, swollen testes and swollen joints as symptoms of brucellosis had no impact on infertility, our findings that symptoms associated with brucellosis are consistent with earlier in vitro studies on rat models that demonstrated that $B$. abortus infection induced 
Table 4 Reported impact of swollen testes on socio-economic status

\begin{tabular}{|c|c|c|c|c|c|c|c|c|c|}
\hline \multirow[t]{3}{*}{ Variables } & \multicolumn{4}{|c|}{ Swollen testes ${ }^{a}$} & \multirow[t]{3}{*}{$x^{2}$} & \multirow[t]{3}{*}{$P$-value } & \multirow[t]{3}{*}{$O R$} & \multirow[t]{3}{*}{$95 \% \mathrm{Cl}$} & \multirow{3}{*}{$\begin{array}{l}P- \\
\text { value }\end{array}$} \\
\hline & \multicolumn{2}{|l|}{ Yes } & \multicolumn{2}{|l|}{ No } & & & & & \\
\hline & $n$ & $\%$ & $n$ & $\%$ & & & & & \\
\hline \multicolumn{10}{|l|}{ Milk } \\
\hline High & 14 & 8.8 & 96 & 20.0 & 11.3 & $0.004^{*}$ & 1.688 & $0.964-2.957$ & 0.670 \\
\hline Medium & 93 & 58.5 & 231 & 48.0 & & & & & \\
\hline Low & 52 & 32.7 & 154 & 32.0 & & & & & \\
\hline \multicolumn{10}{|c|}{ Meat and blood } \\
\hline High & 8 & 5.0 & 70 & 14.6 & 12.7 & $0.002^{*}$ & 0.942 & $0.525-1.689$ & 0.841 \\
\hline Medium & 101 & 63.5 & 245 & 50.9 & & & & & \\
\hline Low & 50 & 31.4 & 166 & 34.5 & & & & & \\
\hline \multicolumn{10}{|l|}{ Fat } \\
\hline High & 2 & 1.3 & 34 & 7.1 & 9.3 & 0.100 & 0.730 & $0.435-1.225$ & 0.233 \\
\hline Medium & 96 & 60.4 & 247 & 51.4 & & & & & \\
\hline Low & 61 & 38.4 & 200 & 41.6 & & & & & \\
\hline \multicolumn{10}{|l|}{ Infertility } \\
\hline High & 40 & 25.2 & 194 & 40.3 & 11.9 & $0.003^{*}$ & & & \\
\hline Medium & 62 & 39.0 & 148 & 30.8 & & & 1.046 & $0.644-1.696$ & 0.857 \\
\hline Low & 57 & 35.8 & 139 & 28.9 & & & & & \\
\hline \multicolumn{10}{|l|}{ Sale value } \\
\hline High & 9 & 5.7 & 78 & 16.2 & 23.8 & $<0.0001^{*}$ & 0.641 & $0.365-1.125$ & 0.122 \\
\hline Medium & 113 & 71.1 & 240 & 49.9 & & & & & \\
\hline Low & 37 & 23.3 & 163 & 33.9 & & & & & \\
\hline \multicolumn{10}{|l|}{ Dowry } \\
\hline High & 2 & 1.3 & 51 & 10.6 & 15.4 & $<0.0001^{*}$ & 5.351 & $1.159-24.706$ & $0.032^{*}$ \\
\hline Medium & 88 & 55.3 & 216 & 44.9 & & & & & \\
\hline Low & 69 & 43.4 & 214 & 44.5 & & & & & \\
\hline \multicolumn{10}{|c|}{ Cost of treatment } \\
\hline High & 52 & 32.7 & 226 & 47.0 & 21.9 & $<0.0001^{*}$ & 0.078 & $0.010-0.598$ & $0.014^{*}$ \\
\hline Medium & 106 & 66.7 & 226 & 47.0 & & & & & \\
\hline Low & 1 & 0.6 & 29 & 6.0 & & & & & \\
\hline
\end{tabular}

apearson Chi-square. *Statistically significant at $P \leq 0.05$. OR odds ratio, 95\% Cl 95\% Confidence Interval. OR generated through logistic regression analyses

$41.67 \%$ infertility in the infected rats [19]. In the study conducted in Korea, they concluded that B. abortus biotype 1 infections in rat models affect reproduction adversely by causing infertility, stillbirth and loss of number and weight of offspring. To date, no studies has been carried out extensively on the impact of brucellosis on livestock. We report for the first time that livestock with suspected brucellosis infection have increased risk to infertility potentially resulting from abortion- and still birth-related complications.

In terms of sale value, there was $62 \%$ reduction on sale value $(\mathrm{OR}=0.385,95 \% \mathrm{CI}=0.190-0.776, P=0.008)$ resulting from abortion, and 3 times reduction in sale value $(\mathrm{OR}=2.963,95 \% \mathrm{CI}=1.258-6.982, \quad P=0.013)$ resulting from weak calf/lamb. However, stillbirth, swollen testes and swollen joints had no impact on sale value in this region. Other analyses demonstrated that for dowry, which is a form of appreciation and which is usually provided in the form of livestock in this set-up, there was 5 times more impact on dowry $(\mathrm{OR}=5.351,95 \% \mathrm{CI}=1.159-24.706, P=$ 0.032) whenever they had swollen testes, $64 \%$ likelihood of reduction of dowry value $(\mathrm{OR}=0.364,95 \% \mathrm{CI}=0.157$ $0.845, P=0.019)$ resulting from weak calf and lambs. However, abortion, stillbirth and swollen joints as symptoms of suspected brucellosis had no impact on dowry. Even though not evaluated previously, we have established that livestock with symptoms associated with brucellosis had a significant reduction in sale value, more so if they had documented abortion and weak calves or lambs. This is tied more closely to payment of dowry in this community as 
Table 5 Reported impact of weak calf or lamb on socio-economic status

\begin{tabular}{|c|c|c|c|c|c|c|c|c|c|}
\hline \multirow[t]{3}{*}{ Variables } & \multicolumn{4}{|c|}{ Weak calf or lamba } & \multirow[t]{3}{*}{$x^{2}$} & \multirow[t]{3}{*}{ P-value } & \multirow[t]{3}{*}{$O R$} & \multirow[t]{3}{*}{$95 \% \mathrm{Cl}$} & \multirow{3}{*}{$\begin{array}{l}P- \\
\text { value }\end{array}$} \\
\hline & \multicolumn{2}{|c|}{ Yes } & \multicolumn{2}{|l|}{ No } & & & & & \\
\hline & $n$ & $\%$ & $n$ & $\%$ & & & & & \\
\hline \multicolumn{10}{|l|}{ Milk } \\
\hline High & 20 & 8.7 & 90 & 22.0 & 24.6 & $<0.0001^{*}$ & 1.113 & $0.668-1.855$ & 0.680 \\
\hline Medium & 142 & 61.7 & 182 & 44.3 & & & & & \\
\hline Low & 68 & 29.6 & 138 & 33.7 & & & & & \\
\hline \multicolumn{10}{|c|}{ Meat and blood } \\
\hline High & 13 & 5.6 & 65 & 15.9 & 19.4 & $<0.0001^{*}$ & 0.818 & $0.477-1.401$ & 0.464 \\
\hline Medium & 146 & 63.5 & 200 & 48.8 & & & & & \\
\hline Low & 71 & 30.9 & 145 & 35.3 & & & & & \\
\hline \multicolumn{10}{|l|}{ Fat } \\
\hline High & 7 & 3.0 & 29 & 7.1 & 7.1 & $0.029^{*}$ & 1.462 & $0.501-4.261$ & 0.487 \\
\hline Medium & 136 & 59.2 & 207 & 50.5 & & & & & \\
\hline Low & 87 & 37.8 & 174 & 42.4 & & & & & \\
\hline \multicolumn{10}{|l|}{ Infertility } \\
\hline High & 70 & 30.5 & 164 & 40.0 & 17.1 & $<0.0001^{*}$ & 0.525 & $0.333-0.827$ & $0.005^{*}$ \\
\hline Medium & 99 & 43.0 & 111 & 27.1 & & & & & \\
\hline Low & 61 & 26.5 & 135 & 32.9 & & & & & \\
\hline \multicolumn{10}{|l|}{ Sale value } \\
\hline High & 12 & 5.2 & 75 & 18.3 & 27.9 & $<0.0001^{*}$ & 2.963 & $1.258-6.982$ & $0.013^{*}$ \\
\hline Medium & 153 & 66.5 & 200 & 48.8 & & & & & \\
\hline Low & 65 & 28.3 & 135 & 32.9 & & & & & \\
\hline \multicolumn{10}{|l|}{ Dowry } \\
\hline High & 17 & 7.4 & 36 & 8.8 & 6.0 & 0.052 & 0.364 & $0.157-0.845$ & $0.019 *$ \\
\hline Medium & 124 & 53.9 & 180 & 43.9 & & & & & \\
\hline Low & 89 & 38.7 & 194 & 47.3 & & & & & \\
\hline \multicolumn{10}{|c|}{ Cost of treatment } \\
\hline High & 80 & 34.8 & 198 & 48.3 & 24.9 & $<0.0001^{*}$ & 0.178 & $0.051-0.622$ & $0.007^{*}$ \\
\hline Medium & 147 & 63.9 & 185 & 45.1 & & & & & \\
\hline Low & 3 & 1.3 & 27 & 6.6 & & & & & \\
\hline
\end{tabular}

apearson Chi-square. *Statistically significant at $P \leq 0.05$. OR odds ratio, 95\% Cl 95\% Confidence Interval. OR generated through logistic regression analyses

they always conduct a thorough examination on livestock intended for the purposes of dowry payment by carrying out physical examination and asking historical questions about their offspring. All these approaches, as they may seem trivial at face-value, add up to form strong and deeply engrained attitudes that are based on culture and tradition, which then affect the socio-economic status of the families involved. More studies, however, need to be conducted to further assess the impacts on sale value and dowry in the context of a variety of nomadic and non-nomadic communities, especially in areas where the true prevalence of brucellosis has been established.

Finally, in terms of cost of treatment, there was 56\% increment on cost of treatment $(\mathrm{OR}=0.449,95 \% \mathrm{CI}=$ $0.281-0.717, P=0.001$ ) resulting from abortion, $80 \%$ increment on cost of treatment in suspected brucellosis cases $\quad(\mathrm{OR}=0.208, \quad 95 \% \quad \mathrm{CI}=0.059-0.738, \quad P=0.015)$ resulting from still births, $22 \%$ increment on cost of treatment $(\mathrm{OR}=0.78,95 \% \mathrm{CI}=0.10-0.598, P=0.014)$ resulting from swollen testes, $83 \%$ increment in cost of treatment $(\mathrm{OR}=0.178,95 \% \mathrm{CI}=0.051-0.622, P=0.007)$ resulting from weak calf or lamb and a $79 \%$ likely increase in cost of treatment $(\mathrm{OR}=0.217,95 \% \mathrm{CI}=0.79$ 0.594, $P=0.003$ ) resulting from swollen joints. This demonstrates that the cost of treatment significantly increases in the presence of all the symptoms associated with brucellosis in this community. A number of economic studies have been conducted in other countries highlighting the potential losses for livestock producers and the general economy from brucellosis, with the 
Table 6 Reported impact of swollen joints on socio-economic status

\begin{tabular}{|c|c|c|c|c|c|c|c|c|c|}
\hline \multirow[t]{3}{*}{ Variables } & \multicolumn{4}{|c|}{ Swollen joints ${ }^{a}$} & \multirow[t]{3}{*}{$x^{2}$} & \multirow[t]{3}{*}{$P$-value } & \multirow[t]{3}{*}{$O R$} & \multirow[t]{3}{*}{$95 \% \mathrm{Cl}$} & \multirow[t]{3}{*}{$P$-value } \\
\hline & \multicolumn{2}{|c|}{ Yes } & \multicolumn{2}{|l|}{ No } & & & & & \\
\hline & $n$ & $\%$ & $n$ & $\%$ & & & & & \\
\hline \multicolumn{10}{|l|}{ Milk } \\
\hline High & 13 & 12.7 & 24 & 12.8 & 28.4 & $<0.0001^{*}$ & 2.881 & $1.733-4.790$ & $<0.0001^{*}$ \\
\hline Medium & 31 & 30.4 & 114 & 6.06 & & & & & \\
\hline Low & 58 & 56.9 & 50 & 26.6 & & & & & \\
\hline \multicolumn{10}{|c|}{ Meat and blood } \\
\hline High & 12 & 11.8 & 22 & 11.7 & 16.1 & $<0.0001^{*}$ & 1.561 & $0.921-2.644$ & 0.980 \\
\hline Medium & 38 & 37.2 & 113 & 60.1 & & & & & \\
\hline Low & 52 & 51.0 & 53 & 28.2 & & & & & \\
\hline \multicolumn{10}{|l|}{ Fat } \\
\hline High & 7 & 6.9 & 11 & 5.9 & 4.3 & 0.114 & 0.679 & $0.432-1.067$ & 0.093 \\
\hline Medium & 49 & 48.0 & 114 & 60.6 & & & & & \\
\hline Low & 46 & 45.1 & 63 & 33.5 & & & & & \\
\hline \multicolumn{10}{|l|}{ Infertility } \\
\hline High & 53 & 52.0 & 48 & 25.5 & 22.1 & $<0.0001^{*}$ & 1.126 & $0.720-1.762$ & 0.603 \\
\hline Medium & 33 & 32.3 & 78 & 41.5 & & & & & \\
\hline Low & 16 & 15.7 & 62 & 33.0 & & & & & \\
\hline \multicolumn{10}{|l|}{ Sale value } \\
\hline High & 11 & 10.8 & 19 & 10.1 & 19.8 & $<0.0001 *$ & 0.758 & $0.464-1.236$ & 0.267 \\
\hline Medium & 44 & 43.1 & 128 & 68.1 & & & & & \\
\hline Low & 47 & 46.1 & 41 & 21.8 & & & & & \\
\hline \multicolumn{10}{|l|}{ Dowry } \\
\hline High & 12 & 11.8 & 14 & 7.4 & 13.5 & $0.001^{*}$ & 1.093 & $0.684-1.746$ & 0.711 \\
\hline Medium & 35 & 34.3 & 107 & 56.9 & & & & & \\
\hline Low & 55 & 53.9 & 67 & 25.6 & & & & & \\
\hline \multicolumn{10}{|c|}{ Cost of treatment } \\
\hline High & 61 & 59.8 & 59 & 31.4 & 22.5 & $<0.0001^{*}$ & 0.217 & $0.079-0.594$ & $0.003 *$ \\
\hline Medium & 40 & 39.2 & 122 & 64.9 & & & & & \\
\hline Low & 1 & 1.0 & 7 & 3.7 & & & & & \\
\hline
\end{tabular}

apearson Chi-square. *Statistically significant at $P \leq 0.05$. OR odds ratio, 95\% Cl 95\% Confidence Interval. OR generated through logistic regression analyses

largest losses mainly affecting developing nations [2]. However, the costs of treatment as an impact still remains elusive in developing countries due to lack of comprehensive field and experimental data. Even though we established from the respondents that all the brucellosis symptoms tested in the current study (i.e. abortion, still births, swollen testes, weak calves/lambs and swollen joints) had a higher likelihood of having an increased cost of treatment, a further model incorporating both animal and human aspects in a longitudinal set-up need to be developed. The results are, however, consistent with other observations [20] that showed a significant impact on the costs of treatment on brucellosis-infected yaks in Tibet. Even though not assessed in the current study, respondents who mentioned high costs involved in the treatment of brucellosis were less likely to choose a government health facility compared to a private health facility [21], a pointer that there are huge costs involved in the treatment of brucellosis.

Even though some of the symptoms of suspected brucellosis were not associated with any of the production (e.g. fat, meat and blood production) and reproduction performance, we fully agree with the previous study that highlights a 'One Health' approach to tackling the menace of brucellosis by having a holistic approach into the prevalence of brucellosis in both humans and their livestock in the same household $[5,6]$ and by extension, identifying factors that may additionally lead to significant socio-economic impact. The evaluation of the cost of brucellosis should take into account the cost of the 
human disease, and for this purpose an investigation of the prevalence of the different Brucella species in humans is required, as well as establishing the direct and indirect cost resulting from the infections in humans. In addition, enhanced support from the government and the private sector, in accessing insecurity-prone areas (such as Baringo County) could sustain brucellosis control campaigns, as they also need to benefit from these control measures.

\section{Conclusion}

Even though there was a huge socio-economic impact on milk production, infertility, sale value, and dowry, it was the costs of treatment that was significantly impacted on all symptoms associated with brucellosis on this community. A 'One Health' approach to tackling the brucellosis menace as a holistic approach is urgently needed to address the prevalence of brucellosis in both humans and their livestock in the same households.

\section{Methods}

\section{Study area}

Baringo County is situated in the Rift Valley Region and shares borders with 8 counties namely, West Pokot to the North West, Turkana to the North, Samburu to the North East, Laikipia to the East, Nakuru to the South, Kericho and Uasin-Gishu Counties to the South West, and ElgeyoMarakwet to the West. The County is divided into 6 SubCounties, namely Baringo South, Mogotio, Eldama Ravine, Baringo Central, Baringo North and Tiaty. It is predominantly inhabited by the Tugen, Pokot and Ilchamus ethnic groups, who are livestock keepers; with minority groups such as Endorois, Nubians, Ogiek, Kikuyu and Turkana. The Tugens mostly practice agro-pastoralism. This mixture of land use allows for complex human-animal interactions usually compounded by the high population density and diversity [15]. It is these complex dynamics that our study was aiming to unravel with respect to brucellosis. Baringo County is classified as arid and semi-arid. Most parts of East Pokot, Baringo Central, Baringo South, Baringo North and Mogotio sub-counties are arid and semi-arid except for Eldama Ravine Sub-County which is a highland zone. The rainfall varies from $1000 \mathrm{~mm}$ to $1500 \mathrm{~mm}$ in the highlands to $600 \mathrm{~mm}$ per annum in the lowlands. The sub-counties due to their varied altitudes receives different levels of rainfall. Eldama Ravine SubCounty receives the highest amount of rainfall. The lowlands sub-counties of Mogotio, East Pokot and Baringo North receive up to $600 \mathrm{~mm}$ of rainfall per year. The region is occupied by nomadic communities that place qualifies it as a higher risk region for brucellosis prevalence.

\section{Study design}

The study was carried out in Koibatek (in Eldama Ravine Sub-County) and Marigat (in Baringo South SubCounty) within Baringo County (See Fig. 1). These 2 regions were purposively selected since they were the only agro-pastoral (Koibatek) and arid (Marigat) communities in Baringo County. To realize the objectives of this research, a cross-sectional study applying quantitative approach of data collection was adopted.

\section{Study population and sampling procedures}

Study population The study population consisted of farmers, herders and their livestock (sheep, goats, cattle and camels) from Koibatek and Marigat sub-counties. Majority of livestock were owned by pastoralists who migrate throughout the dry season looking for pastures in small groups of families or in large groups of villages [15]. In effect, the herds in each grouping can be owned by more than one family, but usually it is a herd per family.

Sample size determination The sample size was determined by Cochran formula [22] which allowed for the calculation of an ideal sample size given a desired level of precision, confidence interval and the estimated proportion of attribute present in the population. Population proportion estimated to the prevalence of brucellosis was $30 \%$ in an animal herd, an absolute precision of $5 \%$ and at 95\% confidence level adopted for this study. Based on these estimates, the final sample size obtained was 640 herds of domestic ruminants comprising of 320 bovines, 154 goats, 106 camels and 60 sheep in 604 households.

Sampling procedure Probability sampling techniques using cluster and simple random methods was used to practically access households that had domestic ruminants. A random sample of 50 villages was selected using a table of random numbers which gave 30 pastoral villages from Marigat and 20 agro-pastoral villages from Koibatek. The team, trained on the data collection instruments and ethical issues, comprised of two enumerators who covered at least one village in a day to administer a minimum of 8 questionnaires at random and these were uploaded in Open Data Kit (ODK) in real-time. Once the team was within the prescribed geocode, the compound to be assessed was identified using the 'spin bottle method.' Using a flat surface, the enumerator could spin the bottle until it settled and take the direction facing the mouth of the bottle until he/she reached a household with a domestic ruminant. The first household in that direction was selected and the team entered into the household to administer the questionnaire. The consent was first sought from respondent before proceeding with the questionnaire administration. 


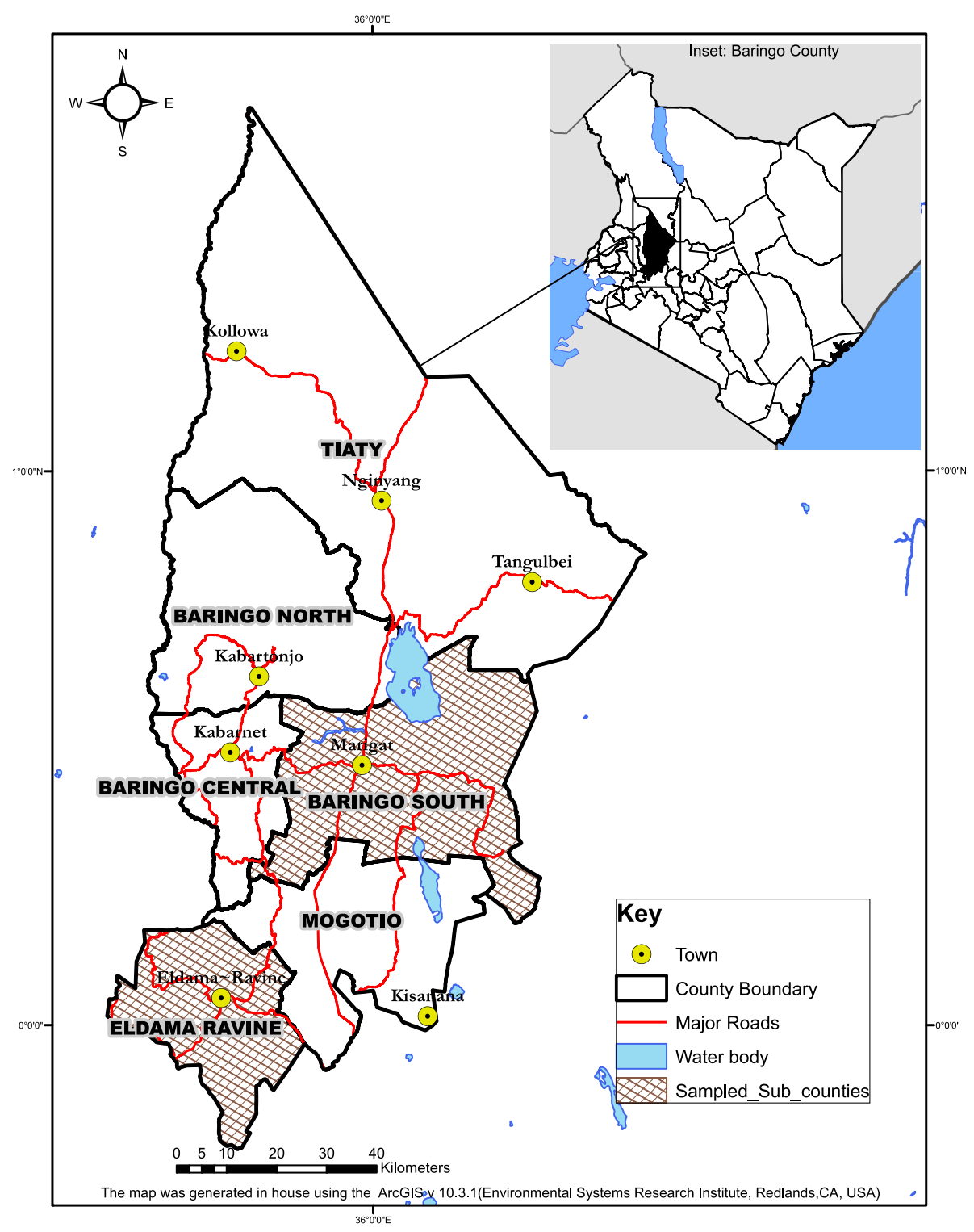

Fig. 1 The figure shows the map of the study site within Baringo County. The map was created using ArcGIS (version 10.31) software by Esri.ArcGIS ${ }^{\oplus}$ and $\operatorname{ArcMap}^{\mathrm{TM}}$ are the intellectual property of Esri and are used herein under license. Copyright@ Esri. All rights reserved. For more information about Esri ${ }^{\circledR}$ software, please visit www.esri.com

Once the respondent in the first household gave consent and agreed to be interviewed by the enumerator, the enumerator, stood at the door of the just completed house and spun the bottle again to pick the direction of the mouth of the next bottle. The enumerator again walked to the next household until all eight eligible households were interviewed. An enumerator that reached the end of the village before completing the numbers required, went back to the center of the village and span the bottle once again. In case the enumerator double-selected the previous household, that household was excluded and the exercise was repeated until another eligible household with domestic ruminants was selected.

\section{Methods of data collection}

Quantitative data was collected using the Open Data Kit (ODK) software that captured the perceived socio-economic effects on livestock production and reproduction performance. These were pre-tested and customized accordingly prior to actual administration. The data collection exercise was conducted in Tugen, the local language, Kiswahili or in special cases, where the respondent was knowledgeable, in English.

Questionnaire interview method The questionnaire was administered to each respondent by an enumerator for a period of $35 \mathrm{~min}$. During the interview process, focus 
was on: respondent's perceived socio-economic impact of brucellosis on livestock production and reproduction performance with a focus on milk, meat and blood, and fat production, infertility, sale value, dowry and cost of treatment relative to suspected brucellosis symptoms (abortions, still births, swollen testes, weak calf or lamb, and swollen joints) (See Supplementary file 1).

\section{Statistical analysis}

Data analysis adopted the use of descriptive and inferential statistics. Descriptive statistics were used to characterize different frequencies. Pearson Chi-square was used to establish the proportionality between the parameters. Logistic regression was further used to establish associations between the symptoms (suspected brucellosis symptoms) and likelihood impacts on milk, meat and blood, and fat production, infertility, sale value, dowry and cost of treatment. All $P$-values $\leq 0.05$ were considered statistically significant.

\section{Supplementary information}

Supplementary information accompanies this paper at https://doi.org/10 1186/s12917-020-02283-w.

Additional file 1. This is the raw data generated from the quantitative questionnaire administered to the respondents.

\section{Abbreviations}

Cl: Confidence interval; FAO: Food and Agricultural Organizations;

LMICs: Low- and middle-income countries; ODK: Open data kit; OIE: World

Organization for Animal Health; OR: Odd ratio

\section{Acknowledgements}

We would like to express our gratitude to Baringo County veterinary and laboratory staff for their cooperation during the study. This study would not have been realized without voluntary participation of participants from Marigat and Koibatek Sub-Counties of Baringo County, Kenya.

\section{Authors' contributions}

PNL, MAK and CO conceived and designed the study. PNL, MAK, HA, SG and $\mathrm{CO}$ drafted the manuscript and performed data analysis. All authors have read and approved the manuscript.

\section{Funding}

N/A.

\section{Availability of data and materials}

The datasets used and/or analyzed during the current study are available from the corresponding author on reasonable request.

\section{Ethics approval and consent to participate}

This study was ethically approved by Maseno University Ethical Review Committee (REF: MSU/DRPI/MUERC/00600/18) and was conducted according to Helsinki's declaration. Written informed consent was obtained from all participants and confidentiality was ensured throughout the study.

\section{Consent for publication}

Not applicable.

\section{Competing interests}

The authors declare that they have no competing interests.

\section{Author details}

'Department of Public Health, School of Public Health and Community Development, Maseno University, Kisumu, Kenya. ${ }^{2}$ Department of Disease Surveillance and Epidemic Response, Ministry of Health, Nairobi, Kenya. ${ }^{3}$ Kenya Nutritionists and Dieteticians Institute, Nairobi, Kenya. ${ }^{4}$ Department of Religion, Theology and Philosophy, School of Arts and Social Sciences, Maseno University, Kisumu, Kenya. ${ }^{5}$ Department of Biomedical Sciences and Technology, School of Public Health and Community Development, Maseno University, Kisumu, Kenya.

Received: 19 November 2019 Accepted: 11 February 2020 Published online: 18 February 2020

\section{References}

1. Dean AS, Crump L, Greter H, Hattendorf J, Schelling E, Zinsstag J. Clinical manifestations of human brucellosis: a systematic review and meta-analysis. PLoS Negl Trop Dis. 2012;6(12):e1929.

2. McDermott J, Grace D, Zinsstag J. Economics of brucellosis impact and control in low-income countries. Rev Sci Tech. 2013;32(1):249-61.

3. Viana M, Shirima GM, John KS, Fitzpatrick J, Kazwala RR, Buza JJ, Cleaveland S, Haydon DT, Halliday JE. Integrating serological and genetic data to quantify cross-species transmission: brucellosis as a case study. Parasitology. 2016;143(7):821-34.

4. Lakew BT, Fayera T, Ali YM. Risk factors for bovine mastitis with the isolation and identification of Streptococcus agalactiae from farms in and around Haramaya district, eastern Ethiopia. Trop Anim Health Prod. 2019:51(6):1507-13.

5. Munyua P, Bitek A, Osoro E, Pieracci EG, Muema J, Mwatondo A, Kungu M, Nanyingi $M$, Gharpure R, Njenga K, et al. Prioritization of zoonotic diseases in Kenya, 2015. PLoS One. 2016;11(8):e0161576.

6. Simpson G, Marcotty T, Rouille E, Matekwe N, Letesson JJ, Godfroid J. Documenting the absence of brucellosis in cattle, goats and dogs in a "one health" interface in the Mnisi community, Limpopo, South Africa. Trop Anim Health Prod. 2018;50(4):903-6.

7. OIE: Bovine brucellosis. Manual of Diagnostic Tests and Vaccines for Terrestrial Animals. 2011, World Organization for Animal Health, Paris, 2011:1-35.

8. Ducrotoy MJ, Bertu WJ, Ocholi RA, Gusi AM, Bryssinckx W, Welburn S, Moriyon I. Brucellosis as an emerging threat in developing economies: lessons from Nigeria. PLoS Negl Trop Dis. 2014;8(7):e3008.

9. Adamu SG, Atsanda NN, Tijjani AO, Usur AM, Sule AG, Gulani IA. Epidemiological study of bovine brucellosis in three senatorial zones of Bauchi state, Nigeria. Vet World. 2016;9(1):48-52.

10. Eltholth MM, Hegazy YM, El-Tras WF, Bruce M, Rushton J. Temporal analysis and costs of ruminant brucellosis control Programme in Egypt between 1999 and 2011. Transbound Emerg Dis. 2017;64(4):1191-9.

11. Salman MD, King ME, Odde KG, Mortimer RG. Costs of veterinary services and vaccines/drugs used for prevention and treatment of diseases in 86 Colorado cow-calf operations participating in the National Animal Health Monitoring System (1986-1988). J Am Vet Med Assoc. 1991;198(10):1739-44.

12. Zhang N, Huang D, Wu W, Liu J, Liang F, Zhou B, Guan P. Animal brucellosis control or eradication programs worldwide: a systematic review of experiences and lessons learned. Prev Vet Med. 2018;160:105-15.

13. Asakura S, Makingi G, Kazwala R, Makita K. Brucellosis risk in urban and agropastoral areas in Tanzania. EcoHealth. 2018;15(1):41-51.

14. FAO: Health Division. Animal health disease cards-Brucellosis Ovine/Carpine. 2010

15. KNBS: The 2009 Kenya population and housing census, vol. IC. In: Population distribution by age, sex and administrative units. 2010. 2010.

16. Rossetti CA, Arenas-Gamboa AM, Maurizio E. Caprine brucellosis: a historically neglected disease with significant impact on public health. PLoS Negl Trop Dis. 2017:11(8):e0005692.

17. Abebe G, Ike AC, Siegmund-Schultze M, Mane-Bielfeldt A, Valle Zarate A. Prevalence of mastitis and brucellosis in cattle in Awassa and the peri-urban areas of two smaller towns. Zoonoses Public Health. 2010;57(5):367-74.

18. Swai ES, Schoonman L. Human brucellosis: seroprevalence and risk factors related to high risk occupational groups in Tanga municipality, Tanzania. Zoonoses Public Health. 2009;56(4):183-7.

19. Islam MA, Khatun MM, Baek BK, Lee I. Effects of Brucella abortus biotype 1 infection on the reproductive performance of Sprague-Dawley rats. Pak J Biol Sci. 2009:12(4):353-9.

20. Zeng JY, Robertson ID, Ji QM, Dawa YL, Bruce M. Evaluation of the economic impact of brucellosis in domestic yaks of Tibet. Transbound Emerg Dis. 2019;66(1):476-87. 
21. Kansiime C, Rutebemberwa E, Mugisha A, Mugisha S, Asiimwe BB, Rwego IB, Kiwanuka SN. Determinants of patients' choice of provider in accessing brucellosis care among pastoral communities adjacent to lake Mburo National Park in Kiruhura District, Uganda. PloS one. 2014;9(8):e105276.

22. Cochran WG. Sampling techniques. 3rd ed. New York: Wiley; 1977.

\section{Publisher's Note}

Springer Nature remains neutral with regard to jurisdictional claims in published maps and institutional affiliations.

Ready to submit your research? Choose BMC and benefit from:

- fast, convenient online submission

- thorough peer review by experienced researchers in your field

- rapid publication on acceptance

- support for research data, including large and complex data types

- gold Open Access which fosters wider collaboration and increased citations

- maximum visibility for your research: over $100 \mathrm{M}$ website views per year

At BMC, research is always in progress.

Learn more biomedcentral.com/submissions 